\title{
Effects of pavement surface deformations on lane-changing behaviours
}

Metin Mutlu Aydın MSc

PhD candidate, Department of Civil Engineering, Faculty of Engineering, Akdeniz University, Antalya, Turkey (corresponding author:

metinmutluaydin@gmail.com)
Ali Topal PhD

Professor Doctor, Department of Civil Engineering, Faculty of Engineering, Dokuz Eylül University, İzmir, Turkey

Drivers often undertake tactical and safety-related lane-changing (LC) behaviours to minimise their driving effort and travel times under different and complex traffic circumstances. LC behaviour can be affected by various factors such as lane configurations, driver characteristics, pavement surface properties and so on. Pavement surface deformations represent one such factor that forces drivers to change lane. Road surface deformations generally makes driving more difficult and they cause an increase in vehicle operation and maintenance costs. Additionally, they cause many problems, such as traffic congestion and accidents. In this study, the aim is to investigate and explain the effects of pavement surface deformations and other parameters on the LC behaviour of drivers. This study constitutes descriptive research, which uses a logit regression model (LRM) to determine the LC behaviour of drivers. The data set was collected from two different cities (Izmir and Erzurum) and four different deformed road zones in Turkey. It was found that pavement surface deformations have a high impact on the LC behaviour of drivers, and passenger cars are the vehicle type that is most affected by surface deformations. Numerical tests showed that the proposed LRM performs reasonably well in terms of the statistical relationship between LC and effective parameters.

$\begin{array}{ll}\text { Notation } \\ D & \text { depth of deformation } \\ D_{\mathrm{T}^{-1}} & \text { deformation type } 1 \\ D_{\mathrm{T}^{-2}} & \text { deformation type } 2 \\ D_{\mathrm{T}^{-3}} & \text { deformation type } 3 \\ D_{\mathrm{T}}-4 & \text { deformation type } 4 \\ F(.) & \text { function } \\ G(.) & \text { a function taking on values between zero and one } \\ H & \text { height of deformation } \\ n & \text { observation number } \\ P & \text { probability value } \\ u & \text { disturbance term } \\ x & \text { a random variable } \\ x_{j} & \text { partial effect of variable } \\ Y^{*} & \text { latent variable } \\ \alpha_{0} & \text { constant } \\ \alpha_{i} & \text { coefficients of dummy variables } \\ \beta_{j} & \text { coefficients of the variables } \\ \hat{\beta}_{j} & \text { estimator } \\ \varepsilon & \text { error variation } \\ \sigma & \text { standard deviation } \\ \Phi(x) & \text { cumulative distribution function } \\ \phi(z) & \text { normal density function } \\ \chi^{2} & \text { chi-squared } \\ \end{array}$

\section{Introduction}

Lane-changing (LC) behaviour can be defined as a very dangerous driving manoeuvre because of possible driver distraction and blind spots (Alonso et al., 2008). Drivers often perform tactical and safety-related LC behaviours to minimise their driving effort and travel times under different complex traffic circumstances. LC behaviours must be understood, as they have a high impact on traffic flow characteristics (Al-Kaisy et al., 2005; Coifman et al., 2005; Laval and Daganzo, 2006; Moridpour et al., 2010; Toledo and Zohar, 2007). Therefore, understanding and analysis of LC behaviours can provide an important tool in various application fields, such as traffic safety, capacity and traffic flow analysis. Such behaviours can be affected by various factors, for instance, lane configurations, traffic flow conditions, driver characteristics, pavement surface properties and so on (Aydin et al., 2014). LC models usually comprise three steps: $(a)$ decision to change lanes, $(b)$ selection of target lane and $(c)$ implementation of the lane change (Ramanujam, 2007). However, LC behaviours are also categorised as either mandatory (MLC) or discretionary (DLC) in various models (Choudhury et al., 2008; Ramanujam, 2007). MLC is observed when a driver has to leave his/her current lane because of the external forcing traffic characteristics and DLC is observed when a driver is trying to minimise travel times and driving effort.

In the last decade, an increasing number of theoretical and experimental research studies have been conducted to model LC behaviour. To understand and analyse this phenomenon, several LC models have been suggested and used for different traffic problems (Gipps, 1986; Hidas, 2005; Toledo, 2007; Toledo et al., 2005; Wardrop, 1952). Gipps (1986) suggested one of the first LC models to use micro-simulation tools. The model by Gipps (1986) includes several LC situations in traffic lanes and transit lanes. In his study, Gipps mentioned that there are three different questions behind every LC behaviour. They are 'Is lane changing possible?', 'Is lane changing necessary?' and 'Is lane changing desirable?'. The LC models of Gipps led to many later studies for further investigation. In another study, Hidas (2005) developed a merging and an LC 
algorithm. The main elements of these algorithms were determined as free, forced and co-operative LC behaviours. Worrall and Bullen (1970) suggested that LC rates could be predicted, considering LC as individual and separate events. Moridpour et al. (2010) examined and compared the influence of traffic flow characteristics on LC behaviour of heavy vehicle (HV) and passenger car (PC) drivers under the influence of heavy traffic flow on freeways. The results showed differences in the structure of LC behaviour in drivers of HVs and PCs. As a result, LC models relating to HVs and PCs should include differences in their model network and parameters. In their study, Toledo and Zohar (2007) investigated the estimation of LC models by using trajectory data. The results indicated that LC processes are influenced by different traffic conditions, the direction of the change and by the other surrounding vehicles.

In the literature, various researchers have attempted to determine the duration of LC behaviours. Tijerina et al. (1997) calculated LC durations for urban streets as between $3.5 \mathrm{~s}$ and $6.5 \mathrm{~s}$, with a mean of $5.0 \mathrm{~s}$, and those for highways were between $3.5 \mathrm{~s}$ and $8.5 \mathrm{~s}$, with a mean of $5.8 \mathrm{~s}$. Also, Hetrick (1997) used observers to collect data within the vehicle and calculated LC durations ranging from $3.4 \mathrm{~s}$ to $13.6 \mathrm{~s}$, with a mean of $6.0 \mathrm{~s}$. From the study results, he also found that young drivers tended to have shorter LC durations compared to elderly drivers. Lee et al. (2003) conducted another study to collect data using instrumented vehicles that were equipped to gather data automatically. They calculated the mean duration of a single LC behaviour as $6.3 \mathrm{~s}$, with a standard deviation of $2 \cdot 0 \mathrm{~s}$. They also found that $\mathrm{LC}$ to the left lane takes longer when compared with LC to the right lane. However, they did not find any significant differences between LC conducted in two different vehicles. Salvucci and Liu (2002) used a driving simulator system to evaluate and determine LC durations. The mean duration of lane changes was calculated as $5 \cdot 14 \mathrm{~s}$, with a standard deviation of $0.86 \mathrm{~s}$. Aghabayk et al. (2011) reported that HVs carry out LC manoeuvres more fluently by applying lower acceleration/deceleration movements. Generally, the purpose of many of the studies was to categorise driver behaviours associated with LC, merging or car-following behaviours (Kondyli and Elefteriadou, 2011; Soria et al., 2014; Sun and Elefteriadou, 2010).

Gap acceptance behaviours among drivers on freeways have also been investigated in previous studies. In the gap acceptance stage of LC, drivers consider and evaluate the adjoining gaps in the direction of the destination lane. Then they decide to change lane in the chosen direction. Many scientific studies have been conducted to determine and model the distribution of the accepted critical gaps before the LC manoeuvre (Daganzo, 1981).

All existing LC models examine the decision-making process of LC behaviours; however, they generally neglect the statistical modelling of LC behaviours involving the use of effective parameters. The literature review reveals that the studies conducted have been mostly related to the mathematical modelling of LC, determination of the LC durations and gap acceptance. Thus, the literature review clearly reveals that, to date, there has been no study to investigate the relation between pavement surface deformations and LC behaviour. In this study, therefore, the aim was to examine and explain the impacts of pavement surface deformations and other parameters on LC behaviours using a regression model. Specifically, the study has the following goals

- to determine the negative effect of pavement surface deformations statistically by using different parameters - to investigate and quantify the relationship between different parameters (lane width, deformation zone area, decision distance for LC, vehicle speed, gender, vehicle type and vehicle availability in the adjacent lane) and LC characteristics.

\section{Study site and data collection}

To determine the effective parameters in LC behaviours of drivers, the data set was collected from four-lane (two in each direction) roads of two different cities (Izmir and Erzurum) and four different deformed road zones (DRZs 1-4) in Turkey (Figure 1). These zones were selected because they have the following properties

- different flow densities

- uninterrupted flow conditions

- facility to take video recordings from high locations

- parking ban

- visible road surface signs (availability of lane separation)

- road with clear visibility.

These deformed road zones are located in Buca/Izmir (DRZs 1 and 2), Narlıdere/Izmir (DRZ 3) and Çat/Erzurum (DRZ 4). Properties of the examined zones are presented in Table 1.

The data examined were collected for only one road direction by using standard video-recording equipment set up at the higher locations near the deformed road zones for each road section (Figure 2). Data collections were made during peak hours in the morning (8:00 to 8:30 a.m.) and evening (6:00 to 6:30 p.m.), and on different weekdays. Analysis data were obtained by extraction from the recording using digital counter software.

From the counts, the random sampling group of this study was determined as 904 vehicles including passenger cars $(n=747$, mean speed $=62.22 \mathrm{~km} / \mathrm{h}, \sigma=26.34 \mathrm{~km} / \mathrm{h})$, minibuses $(n=46$, mean speed $=50.36 \mathrm{~km} / \mathrm{h}, \sigma=18.88 \mathrm{~km} / \mathrm{h})$, buses $(n=36$, mean speed $=58.61 \mathrm{~km} / \mathrm{h}, \sigma=21.90 \mathrm{~km} / \mathrm{h})$ and trucks $/$ lorries $(n=75$, mean speed $=69.54 \mathrm{~km} / \mathrm{h}, \sigma=18.64 \mathrm{~km} / \mathrm{h}$ ). To gain a better understanding of the differences between LC behaviours, the 


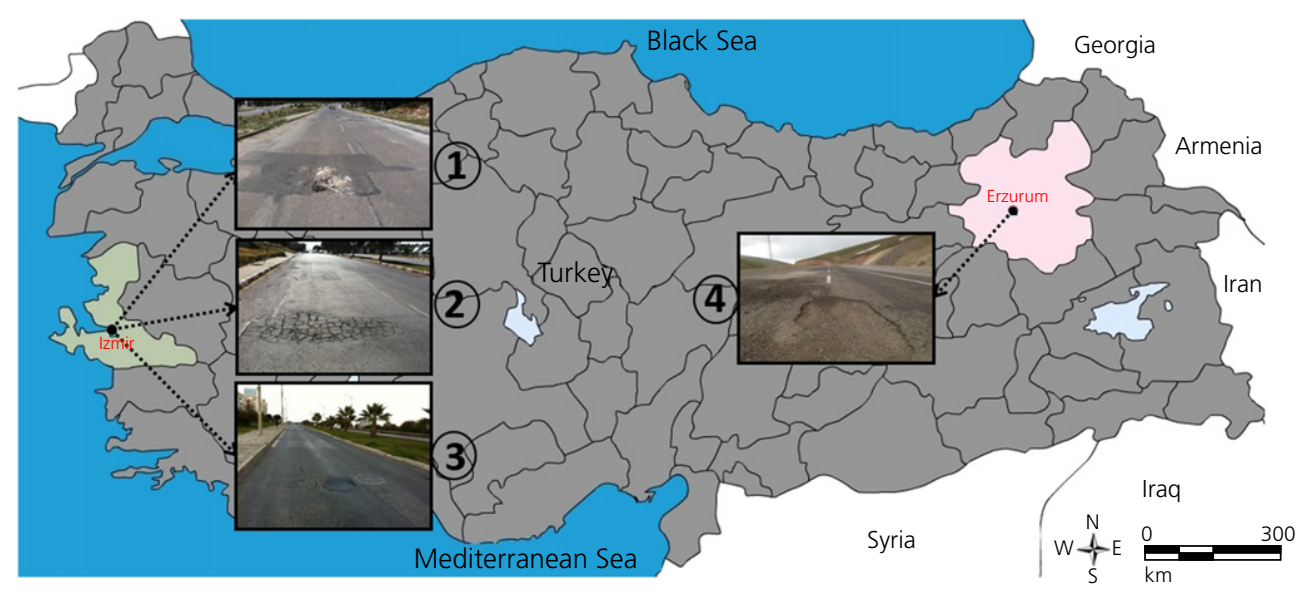

Figure 1. Locations of selected four deformed road zones in Izmir and Erzurum, Turkey

Table 1. Geometrical and structural properties of the four different deformed road zones (DRZs) examined

\begin{tabular}{|c|c|c|c|c|c|c|c|c|c|c|c|}
\hline \multirow[b]{2}{*}{$\begin{array}{l}\text { Zone } \\
\text { no. }\end{array}$} & \multirow[b]{2}{*}{ Lane } & \multirow[b]{2}{*}{$\begin{array}{l}\text { Road } \\
\text { type }\end{array}$} & \multirow[b]{2}{*}{$\begin{array}{l}\text { Area } \\
\text { type }\end{array}$} & \multirow{2}{*}{$\begin{array}{c}\text { Road } \\
\text { width: } \\
\text { m }\end{array}$} & \multirow[b]{2}{*}{ Deformed? } & \multicolumn{5}{|c|}{ Deformation } & \multirow[b]{2}{*}{$\begin{array}{c}\text { Zone } \\
\text { area: } \mathrm{m}^{2}\end{array}$} \\
\hline & & & & & & Type & Width: m & Length: $\mathrm{m}$ & $\begin{array}{c}\text { Depth, } D, \text { or } \\
\text { height, } H: \mathrm{cm}\end{array}$ & $\begin{array}{l}\text { Location on } \\
\text { pavement: } \mathrm{m}\end{array}$ & \\
\hline \multirow[t]{2}{*}{1} & Left & Divided & Urban & $4 \cdot 5$ & Yes & $D_{\mathrm{T}}-1$ & 1 & 1.65 & $16(H)$ & $(5 \cdot 2-6 \cdot 2)$ & $3 \cdot 3$ \\
\hline & Right & & & $4 \cdot 1$ & No & - & - & - & - & - & - \\
\hline \multirow[t]{2}{*}{2} & Left & Divided & Urban & 4.5 & No & - & - & - & - & - & - \\
\hline & Right & & & $4 \cdot 1$ & Yes & $D_{\mathrm{T}}-2$ & 2 & 1,5 & $6 \cdot 7(D)$ & $(1-3)$ & 3 \\
\hline \multirow[t]{2}{*}{3} & Left & Divided & Urban & 3 & No & - & - & - & - & - & - \\
\hline & Right & & & 3 & Yes & $D_{\mathrm{T}}-3$ & $1 \cdot 1$ & $1 \cdot 2$ & $11(D)$ & $(1 \cdot 8-2 \cdot 9)$ & $1 \cdot 3$ \\
\hline \multirow[t]{2}{*}{4} & Left & Undivided & Rural & $4 \cdot 5$ & Yes & $D_{\mathrm{T}}-4$ & 2 & $1 \cdot 7$ & $7 \cdot 5(D)$ & $(2-4)$ & $3 \cdot 4$ \\
\hline & Right & & & $4 \cdot 6$ & No & - & - & - & - & - & - \\
\hline
\end{tabular}

Notes: $D_{\mathrm{T}}-1$ represents 'swelling'; $D_{\mathrm{T}}-2$ represents 'Pothole and high-severity alligator cracking'; $D_{\mathrm{T}}-3$ represents 'High-severity patch, corrugation and shoving'; and $D_{\mathrm{T}}-4$ represents 'Loss of coarse aggregate, ravelling and stripping'

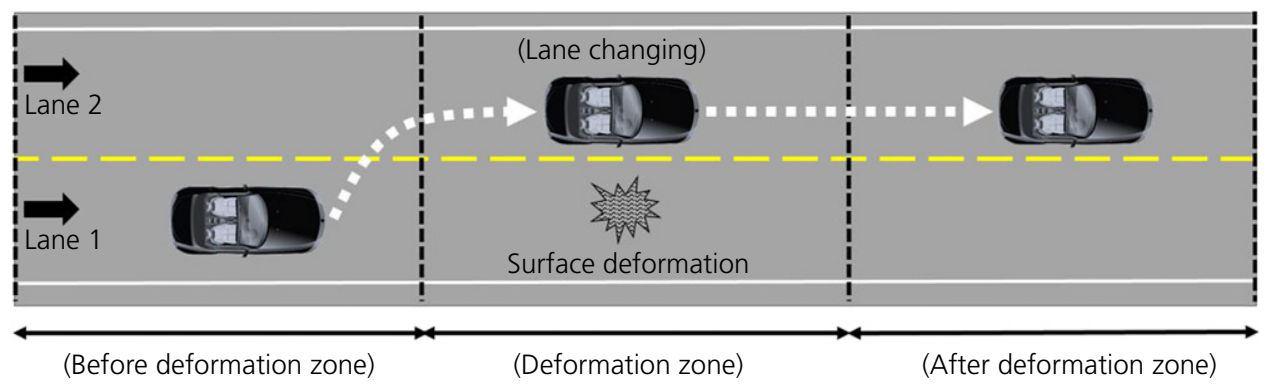

Figure 2. Deformation zone on a two-lane highway and LC behaviour of drivers

obtained data are categorised and summarised in Table 2 according to the effect on the LC behaviours of drivers.

As can be seen in Table 2, 91.9\% and $8 \cdot 1 \%$ of the participants, respectively, are male and female, and $85 \cdot 1 \%$ of males and $52 \cdot 1 \%$ of females have changed lanes. Also, it was found from the site observations that passenger cars are the vehicle type most affected by pavement surface deformations. This is because they have the highest LC percentage (88.8\%) compared with minibuses, buses and trucks/lorries. From the results obtained, it can be said that swelling is the most effective deformation type, because $91 \cdot 2 \%$ of drivers changed their lane to avoid the negative effects of this type of deformation. The ratios for other deformation types can be observed as 
Table 2. Percentage description of obtained data for LC behaviours of drivers

\begin{tabular}{|c|c|c|c|}
\hline \multirow[b]{2}{*}{ Parameters } & \multicolumn{2}{|c|}{ Lane changing? } & \multirow{2}{*}{$\sum_{\text {(percentage) }}^{\text {Sample size }}$} \\
\hline & $\begin{array}{c}\text { Yes } \\
\text { (percentage) }\end{array}$ & $\begin{array}{c}\text { No } \\
\text { (percentage) }\end{array}$ & \\
\hline \multicolumn{4}{|l|}{ Gender } \\
\hline Male & $707(85 \cdot 1)$ & $124(14 \cdot 9)$ & $831(91.9)$ \\
\hline Female & $38(52 \cdot 1)$ & $35(47 \cdot 9)$ & $73(8 \cdot 1)$ \\
\hline Total $(\Sigma)$ & $745(82 \cdot 4)$ & $159(17 \cdot 6)$ & $904(100)$ \\
\hline \multicolumn{4}{|l|}{ Vehicle type } \\
\hline Passenger car & $659(88 \cdot 8)$ & $88(11 \cdot 8)$ & $747(82 \cdot 6)$ \\
\hline Minibus & $31(67 \cdot 4)$ & $15(32 \cdot 6)$ & $46(5 \cdot 1)$ \\
\hline Bus & $19(52 \cdot 8)$ & $17(47 \cdot 2)$ & $36(4)$ \\
\hline Truck/lorry & $36(48 \cdot 0)$ & $39(52)$ & $75(8 \cdot 3)$ \\
\hline Total $\left(\sum\right)$ & $745(82 \cdot 4)$ & $159(17 \cdot 6)$ & $904(100)$ \\
\hline \multicolumn{4}{|l|}{ Deformation type } \\
\hline$D_{\mathrm{\top}}-1$ & $198(91 \cdot 2)$ & $19(8 \cdot 8)$ & $217(24)$ \\
\hline$D_{\mathrm{T}}-2$ & $62(67 \cdot 4)$ & $30(32 \cdot 6)$ & $92(10 \cdot 2)$ \\
\hline$D_{\mathrm{\top}}-3$ & $30(44 \cdot 8)$ & $37(55 \cdot 2)$ & $67(7 \cdot 4)$ \\
\hline$D_{\mathrm{T}}-4$ & $455(86 \cdot 2)$ & $73(13 \cdot 8)$ & $528(58 \cdot 4)$ \\
\hline Total $\left(\sum\right)$ & $745(82 \cdot 4)$ & $159(17 \cdot 6)$ & $904(100)$ \\
\hline \multicolumn{4}{|c|}{ Location of deformation (lane) } \\
\hline Right & $93(57 \cdot 8)$ & $68(42 \cdot 2)$ & $161(17 \cdot 8)$ \\
\hline Left & $652(87 \cdot 8)$ & $91(12 \cdot 2)$ & $743(82 \cdot 2)$ \\
\hline Total $\left(\sum\right)$ & $745(82 \cdot 4)$ & $159(17 \cdot 6)$ & $904(100)$ \\
\hline \multicolumn{4}{|c|}{ Vehicle availability in adjacent lane } \\
\hline Yes & $61(55)$ & $55(45)$ & $116(12 \cdot 8)$ \\
\hline No & $684(86 \cdot 8)$ & $104(13 \cdot 2)$ & $788(87 \cdot 2)$ \\
\hline Total $\left(\sum\right)$ & $745(51 \cdot 7)$ & $159(48 \cdot 3)$ & $904(100)$ \\
\hline \multicolumn{4}{|l|}{ Pavement type } \\
\hline Divided & $291(77 \cdot 4)$ & $85(22 \cdot 6)$ & $376(41 \cdot 6)$ \\
\hline Undivided & $454(86)$ & $74(14)$ & $528(58 \cdot 4)$ \\
\hline Total $\left(\sum\right)$ & $745(82 \cdot 4)$ & $159(17 \cdot 6)$ & $904(100)$ \\
\hline \multicolumn{4}{|l|}{ Road type } \\
\hline Urban & $290(77 \cdot 1)$ & $86(22 \cdot 9)$ & $376(41 \cdot 6)$ \\
\hline Rural & $455(86 \cdot 2)$ & $73(13 \cdot 8)$ & $528(58 \cdot 4)$ \\
\hline Total $(\Sigma)$ & $745(51 \cdot 7)$ & $159(48 \cdot 3)$ & $904(100)$ \\
\hline
\end{tabular}

Note: numbers in parentheses indicate percentage of the examined case

follows: loss of coarse aggregate, ravelling and stripping $(86 \cdot 2 \%)$; stripping and alligator cracking $(67 \cdot 4 \%)$; and highseverity patches, corrugation and shoving (44.8\%). Table 2 also reveals that vehicle availability is another important and restrictive parameter on LC behaviour. If there is no vehicle in the adjacent lane, drivers are more willing to change their lane to avoid any deformation effect $(86 \cdot 8 \%)$.

\section{Methodology}

\subsection{Determination of variables and model}

In the study, an attempt was made to examine the parameters effective in terms of LC. First, all of the effective variables were described as: gender (female/male); vehicle type (passenger car, minibus, bus and truck/lorry); vehicle availability in adjacent lane (yes/no); lane width (m); deformation zone area $\left(\mathrm{m}^{2}\right)$; decision distance for LC $(\mathrm{m})$; and vehicle speed $(\mathrm{km} / \mathrm{h})$. Then all of the effective parameters that had been determined were classified into three groups: dependent variables, continuous variables and dummy variables $(0,1)$ to categorise the predictors as given below.

LC: lane changing behaviour as dependent variable

Continuous variables

lane width (m)

deformation zone area $\left(\mathrm{m}^{2}\right)$

decision distance for $\mathrm{LC}(\mathrm{m})$

vehicle speed $(\mathrm{km} / \mathrm{h})$

Dummy variables

gender (takes the value of 1 if individual is male, 0 otherwise),

vehicle type 2 (takes the value of 1 if vehicle type is minibus, 0 otherwise)

vehicle type 3 (takes the value of 1 if vehicle type is bus, 0 otherwise),

vehicle type 4 (takes the value of 1 if vehicle type is truck/lorry, 0 otherwise),

vehicle availability in adjacent lane (takes the value of 1 if there is a vehicle in the adjacent lane, 0 otherwise).

To determine effective parameters, a logit regression model (LRM) and a probit regression model (PRM) were used. These models contain an admixture of quantitative and qualitative variables, and they are called analysis of covariance (Ancova) models (Ardahan and Mert, 2013; Gujarati, 2003; Mert, 2016). The Ancova model was estimated as given below

$$
\begin{aligned}
\mathrm{LC}= & \alpha_{0}+\alpha_{1} \text { Gender }+\alpha_{2} \text { Vehicle type } 2 \\
& +\alpha_{3} \text { Vehicle type } 3+\alpha_{4} \text { Vehicle type } 4 \\
& +\alpha_{5} \text { Vehicle availability in adjacent lane } \\
& +\beta_{1} \text { Lane width }+\beta_{2} \text { Deformation zone area } \\
& +\beta_{3} \text { Decision distance for lane changing } \\
& +\beta_{4} \text { Vehicle speed }+u
\end{aligned}
$$

In this equation, $\alpha_{0}$ is a constant term; $\alpha_{i}, i \neq 0$ are the coefficients of dummy variables; $\beta_{j}, j=1, \ldots, 4$ indicate the coefficients of the variables in the model; and, finally, $u$ is a disturbance term. Descriptive statistics (means, standard deviations, minimum and maximum values) of numerical variables of the analysis are provided in Table 3. Essentially, it can be observed from Table 3 that the mean decision distance for LC is around $35 \mathrm{~m}$ for the deformed road zones examined. This result shows differences according to vehicle speed, magnitude of deformations, weather conditions, road, driver, vehicle and traffic characteristics.

\subsection{Logit and probit regression models}

The LRMs and PRMs have been used previously in traffic analysis to examine and evaluate traffic accidents, driver 
Table 3. Descriptive statistics results for the numerical variables

\begin{tabular}{|c|c|c|c|c|c|}
\hline Variables & $\begin{array}{l}\text { Sample } \\
\text { size }\end{array}$ & Min. & Max. & Mean & $\sigma$ \\
\hline Lane width: m & 904 & 3 & $4 \cdot 6$ & $4 \cdot 30$ & 0.538 \\
\hline $\begin{array}{l}\text { Deformation zone } \\
\text { area: } \mathrm{m}^{2}\end{array}$ & 904 & $1 \cdot 3$ & $3 \cdot 4$ & $2 \cdot 73$ & 0.863 \\
\hline $\begin{array}{l}\text { Decision distance } \\
\text { for LC: } m\end{array}$ & 461 & $4 \cdot 7$ & $162 \cdot 7$ & $34 \cdot 48$ & $20 \cdot 037$ \\
\hline Vehicle speed: km/h & 904 & $13 \cdot 8$ & $132 \cdot 9$ & $62 \cdot 07$ & $25 \cdot 503$ \\
\hline
\end{tabular}

behaviour and so on (Abdel-Aty et al., 2011; Eluru et al., 2008; Fan and Haile, 2014; Haleem and Abdel-Aty, 2010). In this study, the LRM and PRM were also used to determine the LC behaviour of drivers. In the analysis, the dependent variable of a PRM or LRM could only take two values. Suppose that the analysis was investigating the probability of a deformed zone's effect on drivers' LC behaviour, then $y$ could be 1 if the driver changes lane and 0 otherwise. It was possible to determine the limitations of the PRM or LRM as a linear probability model (LPM); the next relation was assumed as

2. $P(y=1 \mid x)=F\left(\beta_{0}+\beta_{1} x_{1}+\beta_{2} x_{2}+\cdots+\beta_{n} x_{n}\right)$

where $F($.$) is a function and x$ is $[0,1], \forall x \in R$. The logit model consists of a logit (cumulative) distribution, and is defined as follows

3. $F(x)=\frac{\mathrm{e}^{x}}{1+\mathrm{e}^{x}}=\frac{1}{1+\mathrm{e}^{-x}}=\Lambda(x)$

The probit model consists of a normal (cumulative) distribution, and is defined as follows

4. $\quad F(x)=\Phi(x)=\int_{-\infty}^{x} \phi(x) \mathrm{d} x$

5. $\phi(x)=\frac{\mathrm{e}^{\left(x^{2} / 2\right)}}{\sqrt{2 \pi}}$

where $\phi(x)$ is the normal density function.

Suppose that $Y^{*}$ is a latent variable obtained by Equation 6, as given below

6. $Y^{*}=\beta_{0}+\beta_{1} x_{1}+\beta_{2} x_{2}+\cdots+\beta_{n} x_{n}+\varepsilon$

where $\varepsilon \sim N(0,1)$. Then, if this latent variable is positive, $Y$ can be an indicator

7. $Y=\left\{\begin{array}{ll}1 & \text { if } Y^{*}>0 \\ 0 & \text { otherwise }\end{array}\right.$ i.e. $\left(-\varepsilon<\beta_{0}+\beta_{1} x_{1}+\cdots+\beta_{n} x_{n}\right)$
To calculate this function, it is assumed that the expected value of the error terms given the independent variables is 0 . Then, the response probabilities can be derived and obtained as given below

8.

$$
\begin{aligned}
P(Y=1 \mid x) & =P\left(Y^{*}>0 \mid x\right) \\
& =P\left(\varepsilon>0-\beta_{0}-\beta_{1} x_{1}-\beta_{2} x_{2}-\cdots-\beta_{n} x_{n} \mid x\right) \\
& =1-F\left(-\beta_{0}-\beta_{1} x_{1}-\beta_{2} x_{2}-\cdots-\beta_{n} x_{n}\right) \\
& =F\left(\beta_{0}+\beta_{1} x_{1}+\beta_{2} x_{2}+\cdots+\beta_{n} x_{n}\right)
\end{aligned}
$$

To determine the partial effect of variable $x_{j}$, the following equation is used

9. $\frac{\partial F(x \beta)}{\partial x_{j}}=f(x) \beta_{j}$

To calculate continuous variables, Equation 10 is used

10. $n^{-1} \sum_{i=1}^{n} f\left(x_{i} \hat{\beta}\right) \hat{\beta}_{j}$

The equation for dummy variables could be

11. $n^{-1} \sum_{i=1}^{n}\left[G\left(x_{-j} \hat{\beta}_{-j}+x_{j} \hat{\beta}_{j}\right)-G\left(x_{-j} \hat{\beta}_{-j}\right)\right]$

Then Equation 12 is obtained for discrete variables if it increases by the usual unit measure. It can be seen from Equation 12 that there is no limitation for the functional form of the independent variables. Log values and quadratic values of the independent variables can be used in PRMs or LRMs.

12. $n^{-1} \sum_{i=1}^{n}\left\{G\left[x_{-j} \hat{\beta}_{-j}+\left(x_{j+1}+1\right) \hat{\beta}_{j}\right]-G\left(x_{-j} \hat{\beta}_{-j}+x_{j+1} \hat{\beta}_{j}\right)\right\}$

\section{Analysis and findings}

The LRMs and PRMs have the same set of problems. There are small differences between LRMs and PRMs. An LRM uses the odds ratio, whereas a PRM uses the Gaussian (normal distribution) function. The log-likelihood information and McFadden $R^{2}$ values are used in the analysis to decide which regression model is best at describing the relation between LC and the given parameters. In a good model the log-likelihood information and McFadden $R^{2}$ values must have high values (Mert, 2016; Posada and Buckley, 2004). A comparison was made between the LRM and PRM to determine which model is best in describing the relation between LC and the effective parameters (Table 4). As can be seen in 
Table 4. Comparison of logit and probit models

\begin{tabular}{lcc} 
& Logit model & Probit model \\
\hline Probability $>$ likelihood ratio & $0.000^{\mathrm{b}}$ & $0.000^{\mathrm{b}}$ \\
Log-likelihood full model & $-156.47^{\mathrm{a}}$ & -194.85 \\
McFadden's $R^{2}$ & $0.75^{\mathrm{a}}$ & 0.69
\end{tabular}

andicates statistically more significant model

bProbability > likelihood ratio significant at 0.05 level

Table 4, the log-likelihood information and McFadden $R^{2}$ values indicate that the LRM best describes the suggested model, because the LRM has the higher log-likelihood information $(-156 \cdot 47>-194 \cdot 85)$ and McFadden's $R^{2}(0 \cdot 75>0 \cdot 69)$. Thus, the LRM was used in analysis.

According to the LRM used, multicollinearity and model specification error problems must be examined as diagnostic tests. To check out the multicollinearity problem, the variance inflation factor (VIF) was calculated for each covariate in the model. It was found that the maximum value of VIF was 2.40 - that is, not higher than the value of 10 , which is the upper limit of high multicollinearity (Gujarati, 2003); therefore, there is no multicollinearity problem. In addition, the possible model specification error problem was checked in the model. For this purpose, a link test was performed for the model specification (Pregibon, 1980; Tukey, 1949) and was obtained as $\chi^{2}=989 \cdot 22$ and $P>\chi^{2}=0 \cdot 000$. As a result of this test, it was accepted that there is no model specification problem. After checking model specification and multicollinearity, it was assumed that the disturbances are normally distributed because of the size of the sample, 904. Relying on the central limit theorem when the examined sample size is large, the normal distribution can be used for the ordinary least-squares estimates asymptotically even if the disturbances are not distributed normally (Ardahan and Mert, 2013; Baltagi, 2008; Mert, 2016).

The LRM results are given in Table 5. In this model, chisquared statistics (LR $\chi^{2}$ ) were calculated instead of F-statistics in the least-squares regression.

As seen from Table 5, the LRM obtained is significant (likelihood ratio $\left.\chi^{2}=989 \cdot 22, P=0 \cdot 000\right)$. Also it can be seen from Table 5 that the McFadden's $R^{2}$ value was calculated as $0 \cdot 75$. This high McFadden's $R^{2}$ value shows that the suggested model provides a good fit with the examined data. In the model, all four types of continuous variables (lane width, deformation zone area, vehicle speed and decision distance for LC) have significant coefficients. Also, they have positive effects on LC (coefficient $=1.433, \quad P=0.001$ for lane width; coefficient $=$ $0.225, P=0.000$ for decision distance for LC; coefficient $=$ $0.015, P=0.093$ for vehicle speed). Among these, the highest coefficient value belongs to the lane width variable and the lowest coefficient value belongs to the vehicle speed variable. This means that lane width has the most positive effect and vehicle speed has the least positive effect on LC behaviour, compared with the others. These results also show that LC behaviour of the drivers increases when the lane width becomes wider, the decision distance becomes longer and vehicle speed becomes higher. Results from the study by Aydin et al. (2014) support the results of the present study. By contrast, the deformation zone area has a negative coefficient. This means that the deformation zone area has a negative effect on LC behaviour. Additionally, it can be concluded that the LC behaviour of drivers decreases when a deformation zone area becomes larger. In these results, the depth of the deformation zone can be effective. If the depths of the deformed zones are not

Table 5. Logistic regression model (LRM) for lane changing

\begin{tabular}{|c|c|c|c|c|}
\hline Variables & Coefficient & Standard error & $\mathbf{z}$ & $P$ value \\
\hline \multicolumn{5}{|l|}{ Dependent variable: LC } \\
\hline Constant coefficient & $-7 \cdot 732^{c}$ & 1.713 & $-4 \cdot 51$ & 0.000 \\
\hline Lane width: m & $1 \cdot 433^{c}$ & 0.418 & $3 \cdot 43$ & 0.001 \\
\hline Deformation zone area: $\mathrm{m}^{2}$ & $-1.034^{c}$ & 0.325 & $13 \cdot 73$ & 0.001 \\
\hline Decision distance for LC: $\mathrm{m}$ & $0.225^{c}$ & 0.016 & 1.68 & 0.000 \\
\hline Vehicle speed: km/h & $0.015^{a}$ & 0.009 & $2 \cdot 21$ & 0.093 \\
\hline Gender & $1.591^{\mathrm{b}}$ & 0.721 & -1.29 & 0.027 \\
\hline Vehicle type 2 & -0.859 & 0.664 & $-5 \cdot 18$ & 0.196 \\
\hline Vehicle type 3 & $-4 \cdot 536^{c}$ & 0.876 & $-2 \cdot 24$ & 0.000 \\
\hline Vehicle type 4 & $-1.693^{b}$ & 0.757 & $-3 \cdot 01$ & 0.025 \\
\hline Vehicle availability in adjacent lane & $-1 \cdot 493^{c}$ & 0.497 & $-4 \cdot 51$ & 0.003 \\
\hline \multicolumn{5}{|l|}{$N=904$, likelihood ratio $\chi^{2}(2)=989 \cdot 22$, probability $>\chi^{2}=0.000$} \\
\hline \multicolumn{5}{|l|}{ McFadden's $R^{2}=0.75$, Akaike's information criteria $=0.379$} \\
\hline \multicolumn{5}{|l|}{ Max. VIF $=2 \cdot 40$} \\
\hline Linktest:_hatsq $=0.005, P=0.098$ & & & & \\
\hline
\end{tabular}


high values, the driver will not be affected by the deformation and will continue to move in the same direction.

Analysis results show that four of the dummy variables have a significant coefficient and one dummy variable does not have a significant coefficient. All three types of dummy variables (vehicle type 3, vehicle type 4 and vehicle availability in adjacent lane) have significant coefficients. Also, they have negative effects on LC (coefficient $=-4.536, P=0.000$ for vehicle type 3 ; coefficient $=-1.693, P=0.025$ for vehicle type 4 ; coefficient $=-1.493, P=0.003$ for vehicle availability in adjacent lane). Among these, the highest coefficient belongs to the variable vehicle type 3 (bus) and the lowest coefficient belongs to the variable vehicle availability in adjacent lane. This means that vehicle type 3 (bus) has the most and vehicle availability in adjacent lane has the least negative effect on LC behaviour when compared with the others. Vehicle type bus and lorry/truck, as well as vehicle availability in adjacent lane, cause a decrease in LC behaviour. In other words, if the size of vehicles increases, the chance of LC becomes lower. This means that HVs are less affected by the deformation effect. This conclusion supports the findings of the studies by Tanyel et al. (2013) and Aydin et al. (2014).
Gender is one of the main variables in this study, because driving behaviours of male and female drivers have different characteristics. For this reason, their driving bahaviors in a traffic flow should be evaluated differently from each other (Akgol et al., 2014; Caliskanelli and Tanyel, 2016; Sivak and Schoettle, 2011). Analysis results show that the gender variable also has a significant and positive coefficient in the suggested regression model (coefficient $=1.591, \quad P=0.027$ ). Model outputs show that the coefficient of gender has positive values. This indicates that being male has a positive effect on LC behaviour. Females have a lower chance of LC than males. On the other hand, it was seen from the results that the dummy variable for vehicle type 2 (minibus) has no effect on LC in the model, so the coefficient of vehicle type 2 (minibus) is insignificant (coefficient $=-0.859 P=0.196$ for vehicle type 2). This means that the minibus vehicle type does not have an effect on LC.

As shown in Table 6, the predicted LC probability of males $(79 \cdot 8 \%)$ is higher than females $(46 \cdot 2 \%)$. Male drivers have more LC tendency on deformed roads. The passenger car has the highest LC probability compared with the other three vehicle types. This result could be caused by the small size and high manoeuvrability of passenger cars. Also, it can be seen

Table 6. Observed and predicted LC behaviour

\begin{tabular}{|c|c|c|c|c|c|}
\hline Variables & $\begin{array}{c}\text { Observed } \\
\text { yes: \% }\end{array}$ & $\begin{array}{l}\text { Predicted } \\
\text { yes: } \%\end{array}$ & Difference: \% & $\begin{array}{l}\text { Delta-method } \\
\text { standard error }\end{array}$ & $P$ value \\
\hline \multicolumn{6}{|l|}{ Gender } \\
\hline Male & $85 \cdot 1$ & $79 \cdot 8$ & $6 \cdot 2$ & 0.037 & $0.000^{\mathrm{a}}$ \\
\hline Female & $52 \cdot 1$ & $46 \cdot 2$ & $11 \cdot 3$ & 0.176 & $0.008^{a}$ \\
\hline \multicolumn{6}{|l|}{ Vehicle type } \\
\hline Passenger car & 88.8 & $80 \cdot 7$ & $9 \cdot 1$ & 0.039 & $0.000^{a}$ \\
\hline Minibus & $67 \cdot 4$ & $62 \cdot 6$ & $7 \cdot 1$ & $0 \cdot 159$ & $0.000^{a}$ \\
\hline Bus & $52 \cdot 8$ & $46 \cdot 6$ & $11 \cdot 7$ & 0.036 & $0 \cdot 100^{c}$ \\
\hline Truck/lorry & 48.0 & $44 \cdot 3$ & $7 \cdot 7$ & $0 \cdot 183$ & $0.015^{b}$ \\
\hline \multicolumn{6}{|c|}{ Vehicle availability in adjacent lane } \\
\hline Yes & 55 & $49 \cdot 2$ & $10 \cdot 5$ & 0.124 & $0.000^{a}$ \\
\hline No & $86 \cdot 8$ & $83 \cdot 1$ & $4 \cdot 3$ & 0.033 & $0.000^{a}$ \\
\hline \multicolumn{6}{|l|}{ Lane width: $m$} \\
\hline 3.0 & $60 \cdot 6$ & $54 \cdot 0$ & $10 \cdot 8$ & 0.033 & $0.000^{a}$ \\
\hline $4 \cdot 1$ & $58 \cdot 1$ & $53 \cdot 2$ & 8.4 & 0.009 & $0.000^{a}$ \\
\hline $4 \cdot 5$ & $54 \cdot 3$ & $50 \cdot 4$ & $7 \cdot 2$ & 0.011 & $0.000^{a}$ \\
\hline 4.6 & $47 \cdot 4$ & $42 \cdot 6$ & $10 \cdot 1$ & 0.013 & $0.000^{a}$ \\
\hline \multicolumn{6}{|c|}{ Deformation zone area: $\mathrm{m}^{2}$} \\
\hline $1 \cdot 32$ & $66 \cdot 8$ & $61 \cdot 1$ & $8 \cdot 5$ & 0.037 & $0.000^{a}$ \\
\hline 1.65 & $62 \cdot 6$ & $58 \cdot 2$ & $7 \cdot 0$ & 0.028 & $0.000^{\mathrm{a}}$ \\
\hline $3 \cdot 0$ & $54 \cdot 2$ & $50 \cdot 5$ & $6 \cdot 8$ & 0.009 & $0.000^{a}$ \\
\hline $3 \cdot 4$ & 51.9 & $48 \cdot 5$ & $6 \cdot 5$ & 0.012 & $0.000^{a}$ \\
\hline \multicolumn{6}{|c|}{ Decision distance for LC: $m$} \\
\hline 4.7 (min.) & - & $24 \cdot 0$ & - & 0.027 & $0.000^{a}$ \\
\hline $162 \cdot 7$ (max.) & - & 100 & - & 0.000 & $0.000^{a}$ \\
\hline \multicolumn{6}{|c|}{ Vehicle speed: km/h } \\
\hline 13.8 (min.) & - & $48 \cdot 0$ & - & 0.020 & $0.000^{a}$ \\
\hline 123.9 (max.) & - & $56 \cdot 0$ & - & 0.032 & $0.000^{a}$ \\
\hline
\end{tabular}


from Table 6 that LC probability increases when there is an absence of a vehicle in the adjacent lane, or an increase in lane width, decision distance and vehicle speed. In contrast, LC probability decreases when the deformation zone area becomes larger. Vehicle availability in the adjacent lane has a negative effect on LC and causes a decrease in LC probability linearly. If there is no vehicle in the adjacent lane, drivers are more willing to change their lane to avoid the deformation effect.

Figure 3(a) shows the predicted probability percentages of LC for the model according to variation of lane width. The figure shows that, if there is a deformation on the road surface and if lane width increases, the LC probability increases too. Figure 3(b) reveals that LC probability decreases linearly when the deformation zone area becomes larger. From site observations, the decision distance for LC was found to be approximately $35 \mathrm{~m}$ as a mean value. From the suggested model, it was observed that LC probability of vehicles undergoes a parabolic increase in the range between 5 and $55 \mathrm{~m}$, as given in Figure 3(c). The 5-55 m interval can be accepted as the critical distance in which to notice pavement surface deformations and change lanes. One of the most important results of the study can be seen in Figure 3(d), which is that the LC probability of vehicles increases linearly when vehicle speed becomes higher.

\section{Conclusion and suggestions}

In this study, LC behaviours of drivers on a deformed road are examined, using the data collected from four-lane (two in each direction) roads in two different cities and four different deformed road zones, to analyse and discuss the relationship between pavement surface deformations and LC behaviour. For this purpose, all the parameters that have an effect on LC behaviour in deformed roads have been investigated using an LRM. The following conclusions have been obtained.

- The LRM is found to be an effective method to examine and model for the purpose of LC analysis in deformed road zones. It has a good ability to fit the examined data for this study (McFadden's $R^{2}=0 \cdot 75$ ).

- Analysis showed that pavement surface deformations have a positive effect on LC and, in particular, $D_{\mathrm{T}^{-1}}$ (swelling) has the highest effect on LC. This is probably because of the magnitude of the deformation area.

- Male drivers show more of a reaction to avoid the deformation. In summary, they have a greater tendency to change lanes on deformed roads. This is probably because of the differences in perception and response times between male and female drivers. According to this result, it can be

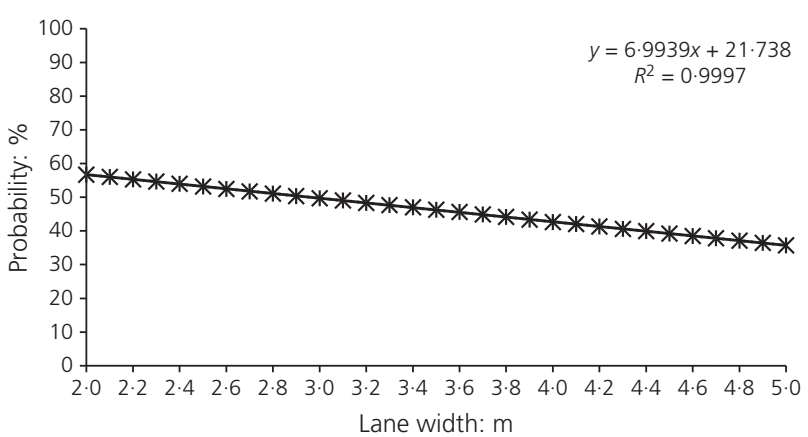

(a)

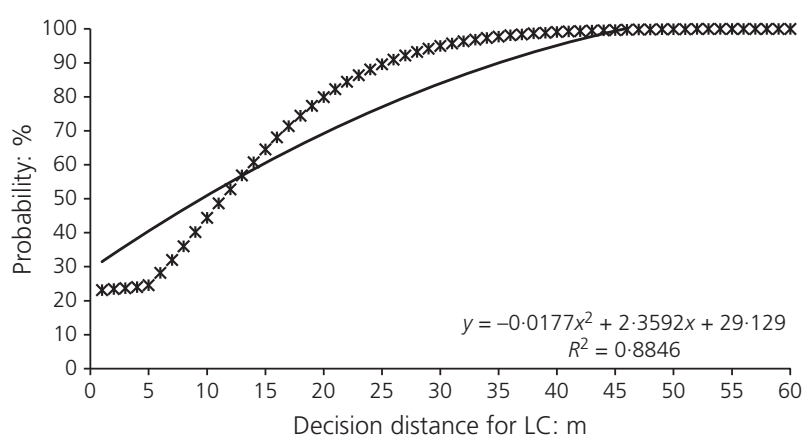

(c)

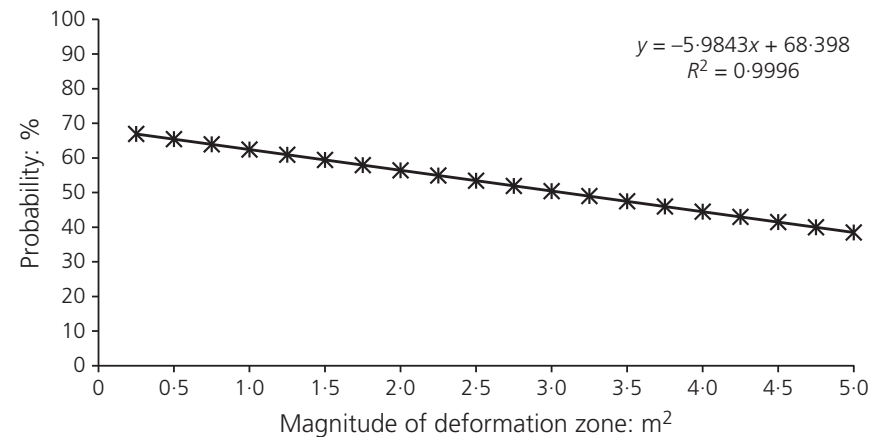

(b)

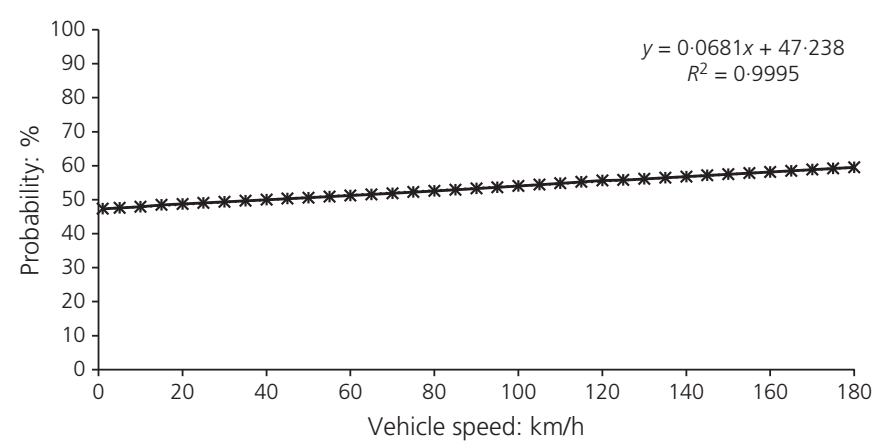

(d)

Figure 3. Predicted LC probabilities (\%) for continuous variables: (a) lane width; (b) magnitude of deformation zone; (c) decision distance for LC; (d) vehicle speed 
concluded that being male has a positive effect on LC behaviour.

- It is known from previous studies that the effect of road deformation is greater for passenger cars than for other vehicle types (Moridpour et al., 2010; Toledo and Zohar, 2007). The findings of this study also showed that passenger cars are the type of vehicle most affected by these deformations and they have the highest $\mathrm{LC}$ ratio to avoid the negative effect of deformations. This is because they are smaller and have higher manoeuvrability to avoid deformations than the other types of vehicles (minibus, bus and lorry/truck).

- The LC decision distance of drivers has been calculated as between 5 and $55 \mathrm{~m}$ from logit regression analysis. This means that the $5-55 \mathrm{~m}$ interval can be accepted as the critical distance before which deformations should be noticed. As can be seen from this result, it is not possible to define a fixed value for LC decision distance. It can vary according to driver characteristics such as gender, driver age, vehicle type, sight distance and so on.

- Vehicles travelling at higher speeds represent an important factor in terms of LC decisions. It has been found that vehicles at higher speeds have a lower tendency to change lanes. According to these results, many parameters can be effective, such as risk perception and the decision-making ability of the driver, traffic flow, sight distance to deformation, vehicle availability in adjacent lane and so on.

- It was found from the analysis that vehicle availability is one of the most critical parameters, because it has a negative linear impact on LC probability. It was concluded from the findings that, if there is no vehicle in the adjacent lane, the drivers of vehicles are more willing to change their lane to avoid the effect of road deformation.

Consequently, the use of an LRM employing the parameters determined can be suggested as a best-fit model to explain the relationship between road surface deformations and LC behaviour, based on the different data availability. Nevertheless, LC behaviour of drivers on deformed road zones should be investigated and compared by using different statistical methods, especially in light of more extended parameters and data gathered from urban and rural roads from different countries and using different data collection methods. In addition, future studies need to include the effects of weather conditions, the age of drivers, slope of the highway, vehicle types in the adjacent lane and other deformation types to estimate the effects of pavement surface deformations on LC behaviour of drivers more comprehensively.

\section{REFERENCES}

Abdel-Aty M, Ekram AA, Huang $\mathrm{H}$ and Choi $\mathrm{K}$ (2011) A study on crashes related to visibility obstruction due to fog and smoke. Accident Analysis and Prevention 43(5): 1730-1737.

Aghabayk K, Moridpour S, Young W, Wang YB and Sarvi M (2011) Investigating heavy vehicle lane changing manoeuvres. Proceedings of the Transportation Research Board 90th Annual Meeting.
Transportation Research Board, Washington, DC, USA, paper no. 11-1586.

Akgol K, Aydin MM, Asilkan Ö and Gunay B (2014) Prediction of modal shift using artificial neural networks. Journal of the Association for Information Communication Technologies 3(3): 223-229.

Al-Kaisy AF, Jung Y and Rakha H (2005) Developing passenger car equivalency factors for heavy vehicles during congestion. Journal of Transportation Engineering 131(7): 514-523.

Alonso JD, Vidal ER, Rotter A and Mühlenberg M (2008) Lane-change decision aid system based on motion-driven vehicle tracking. Vehicular Technology, IEEE Transactions 57(5): 2736-2746.

Ardahan F and Mert M (2013) Impacts of outdoor activities, demographic variables and emotional intelligence on life satisfaction: an econometric application of a case in Turkey. Social Indicators Research 113(3): 887-901.

Aydin MM, Yildirim MS, Karpuz O and Ghasemlou K (2014) Modeling of driver lane choice behavior with artificial neural networks (ANN) and linear regression (LR) analysis on deformed roads. Computer Science \& Engineering: An International Journal (CSEIJ) 4(1): 47-57.

Baltagi BH (2008) Econometrics, 4th edn. Springer, Berlin, Germany. Caliskanelli P and Tanyel S (2016) Investigating the driver's response time at signalized intersections. Transport, http://dx.doi.org/ 10.3846/16484142.2016.1250106.

Choudhury C, Ramanujam V and Ben-Akiva M (2008) Lane changing model for urban arterials. Proceedings of the 3rd International Symposium of Transport Simulation, Gold Coast, Australia.

Coifman B, Krishnamurthy S and Wang X (2005) Lane-Changing Maneuvers Consuming Freeway Capacity. Traffic and Granular Flow '03. Springer, Berlin, Germany.

Daganzo CF (1981). Estimation of gap acceptance parameters within and across the population from direct roadside observation. Transportation Research Part B: Methodological 15(1): $1-15$.

Eluru N, Bhat C and Hensher D (2008) A mixed generalized ordered response model for examining pedestrian and bicyclist injury severity level in traffic crashes. Accident Analysis and Prevention 4(3): 1033-1054.

Fan WD and Haile EW (2014) Analysis of severity of vehicle crashes at highway-rail grade crossings: multinomial logit modeling. Proceedings of the Transportation Research Board 93rd Annual Meeting. Transportation Research Board, Washington, DC, USA, paper no. 14-0588.

Gipps PG (1986) A model for the structure of lane changing decisions. Transportation Research Part B: Methodological 20(5): 403-414.

Gujarati DN (2003) Basic Econometrics, 4th edn. McGraw-Hill, New York, NY, USA.

Haleem K and Abdel-Aty M (2010) Examining traffic crash injury severity at unsignalized intersections. Journal of Safety Research 41(4): 347-357.

Hetrick S (1997) Examination of Driver Lane Change Behavior and the Potential Effectiveness of Warning Onset Rules for Lane Change or 'Side' Crash Avoidance Systems. MSc thesis, Industrial and Systems Engineering, Virginia Tech, Blacksburg, VA, USA.

Hidas P (2005) Modeling vehicle interactions in microscopic traffic simulation of merging and weaving. Transportation Research Part C: Emerging Technologies 13(1): 37-62.

Kondyli A and Elefteriadou L (2011) Modeling driver behavior at freeway-ramp merges. Transportation Research Record 2249: 29-37.

Laval JA and Daganzo CF (2006) Lane-changing in traffic streams. Transportation Research Part B: Methodological 40(3): 251-264.

Lee SE, Olsen ECB and Wierwille WW (2003) A Comprehensive Examination of Naturalistic Lane Changes. National Highway Traffic Safety Administration, US Department of Transportation, 
Effects of pavement surface deformations on lane-changing behaviours

Aydın and Topal
Washington, DC, USA, Report DTNH 22-00-C07007, Task Order 4.

Mert M (2016) Yatay Kesit Veri Analizi Bilgisayar Uygulamaları, 1 st edn. Detay Yayıncilık, Ankara, Turkey (in Turkish).

Moridpour S, Rose G and Sarvi M (2010) Effect of surrounding traffic characteristics on lane changing behavior. Journal of Transportation Engineering 136(11): 973-985.

Posada D and Buckley TR (2004) Model selection and model averaging in phylogenetics: advantages of Akaike information criterion and Bayesian approaches over likelihood ratio tests. Systematic Biology 53(5): 793-808.

Pregibon D (1980) Goodness of link tests for generalized linear models. Applied Statistics 29(1): 15-23.

Ramanujam V (2007) Lane Changing Models for Arterial Traffic. MSc thesis, Department of Civil and Environmental Engineering, Massachusetts Institute of Technology, Cambridge, MA, USA.

Salvucci DD and Liu A (2002) The time course of a lane change: driver control and eye movement behavior. Transportation Research Part F: Traffic Psychology and Behaviour 5(2): 123-132.

Sivak M and Schoettle B (2011) Toward understanding on-road interactions of male and female drivers. Traffic Injury Prevention 12(3): 235-238.

Soria I, Elefteriadou L and Kondyli A (2014) Assessment of car-following models by driver type and under different traffic, weather conditions using data from an instrumented vehicle. Simulation Modelling Practice and Theory 40: 208-220, http://dx.doi.org/ 10.1016/j.simpat.2013.10.002.
Sun DJ and Elefteriadou L (2010) Research and implementation of lane-changing model based on driver behavior. Transportation Research Record 2161: 1-10.

Tanyel S, Caliskanelli SP, Aydin MM and Utku SB (2013) The investigation of heavy vehicle effects on roundabouts. Teknik Dergi 24(119): 6479-6504 (in Turkish).

Tijerina L, Garrott WR, Glecker M, Stoltzfus D and Parmer E (1997) Van and Passenger Car Driver Eye Glance Behavior During Lane Change Decision Phase. National Highway Transportation Safety Administration, US Department of Transportation, Washington, DC, USA, Transportation Research Center, Interim Report.

Toledo T (2007) Driving behavior: models and challenges. Transport Reviews 27(1): 65-84.

Toledo T, Choudhury C and Ben-Akiva M (2005). Lane-changing model with explicit target lane choice. Transportation Research Record 1934: $157-165$.

Toledo T and Zohar D (2007) Modeling duration of lane changes. Transportation Research Record 1999: 71-78.

Tukey JW (1949) One degree of freedom for non-additivity. Biometrics 5(3): 232-242.

Wardrop J (1952) Some theoretical aspects of road traffic research. Proceedings of the Institution of Civil Engineers Part 1 1(3): 325-378.

Worrall RD and Bullen AGR (1970) An empirical analysis of lane changing on multilane highways. Highway Research Record 303(3): $30-43$. 